\title{
INTELIGÊNCIA ARTIFICIAL NA TOMADA DE DECISÕES JUDICIAIS: TRÊS PREMISSAS BÁSICAS ${ }^{1}$
}

\section{ARTIFICIAL INTELLIGENCE IN MAKING JUDICIAL DECISIONS: THREE BASIC PREMISES}

Andre Vasconcelos Roque Doutor e Mestre em Direito Processual pela UERJ. Professor de Direito Processual Civil da UERJ. Sócio de Gustavo Tepedino Advogados. Rio de Janeiro/RJ. E-mail: andreroque@andreroque.adv.br.

Lucas Braz Rodrigues dos Santos Especialista em Direito Tributário e Processo Tributário pela EPD. Pós-graduando em Direito Processual Civil pela PUC/SP. Professor de Direito Processual Civil da ESAMC Santos. Sócio de Braz Advocacia e Consultoria Jurídica. São Paulo/SP. Email: lucasbraz@brazadvocacia.com.

RESUMO: O Poder Judiciário brasileiro enfrenta enorme crise numérica, havendo um contingenciamento processual invencível, de modo que a comunidade jurídica não pode virar as costas para os benefícios da inteligência artificial, porém é preciso que sejam adotados alguns cuidados, garantindo-se a publicidade dos atos judiciais e transparência dos algoritmos, a informação prévia ao jurisdicionado sobre a adoção da inteligência artificial na tomada de decisões, o efetivo acesso à justiça amparado no direito subjetivo de acesso aos juízes e, sobretudo, o direito de revisão das decisões automatizadas sem a utilização dos mecanismos algorítmicos, a fim de que sejam mantidos incólumes os pilares democráticos da república brasileira, em especial o devido processo legal constitucional.

\footnotetext{
${ }^{1}$ Artigo recebido em 06/10/2020 e aprovado em 03/11/2020.
} 
PALAVRAS-CHAVE: Inteligência artificial - tomada de decisões judiciais - princípio da publicidade - dever de informação - acesso à justiça - transparência algorítmica.

\begin{abstract}
The Brazilian Judiciary is facing an enormous numerical crisis, with an invincible procedural contingency, so that the legal community cannot turn its back on the benefits of artificial intelligence, however some care must be taken, ensuring, above all, advertising of judicial acts and transparency of algorithms, prior information to the citizen on the adoption of artificial intelligence in decision making, effective access to justice supported by the subjective right of access to judges and, above all, the right to review automated decisions without use of algorithmic mechanisms, so that the democratic pillars of the Brazilian republic are kept unscathed, especially due to the constitutional legal process.
\end{abstract}

KEY WORDS: Artificial intelligence - judicial decision making - principle of publicity duty of information - access to justice - algorithmic transparency.

\title{
1. A crise numérica do Judiciário e a tecnologia
}

A razoável duração do processo, garantia fundamental inserida no texto constitucional, por meio da $\mathrm{EC} \mathrm{n}^{\circ} 45 / 2004$, apesar de se apresentar como uma promessa ainda longe de ser concretizada na realidade brasileira, é um ideal perseguido pela comunidade jurídica a bem de toda a sociedade.

A morosidade do Poder Judiciário, em que pese a diversidade de fatores que contribuem para esse quadro, é evidente.

O Brasil reúne mais faculdades de direito que China, Estados Unidos da América e Europa juntos. ${ }^{2}$ Segundo o Conselho Federal da OAB ${ }^{3}$ há, atualmente, 1.197 .483 advogados em todo país, o que representa uma proporção estimada de um advogado para cada 190 habitantes. ${ }^{4}$ Evidente, pois, que essa enorme quantidade de profissionais acaba por impactar

\footnotetext{
2 https://g1.globo.com/educacao/guia-de-carreiras/noticia/brasil-tem-mais-faculdades-de-direito-que-chinaeua-e-europa-juntos-saiba-como-se-destacar-no-mercado.ghtml, acesso em 30.5.2020.

${ }^{3}$ https://www.oab.org.br/institucionalconselhofederal/quadroadvogados, acesso em 30.5.2020. 4 https://www.migalhas.com.br/Quentes/17,MI312946,11049Brasil+tem+um+advogado+para+cada+190+habitantes, acesso em 30.5.2020.
} 
no aumento do número de demandas ajuizadas, lembrando que a cada semestre são formados novos profissionais pelas universidades.

Ao lado disso, entre inúmeras outras causas, o incremento da tecnologia através da internet e das plataformas jurídicas, além da facilitação nos meios de acesso à informação e aqui se insere o processo eletrônico e a divulgação de informação pelos próprios sítios online dos tribunais brasileiros -, permitiu que os cidadãos procurassem cada vez mais fazer valer os seus direitos, em processo que se vem incrementando desde a Constituição de 1988 e continua em curso nos dias de hoje. ${ }^{5}$

O resultado disso é que, segundo o relatório Justiça em Números 2019 do CNJ, ${ }^{6}$ ao final do exercício de 2018, o judiciário brasileiro contava com 78.691 .031 processos pendentes, representando um gasto efetivo, descontadas as despesas com servidores inativos, de $\mathrm{R} \$ 76,8$ bilhões, equivalente a 1,1\% do PIB nacional.

Diante desse cenário beligerante, ao lado da tendência de desjudicialização, inclusive por incentivo à utilização dos meios adequados de solução de controvérsias, como, por exemplo, a mediação e a arbitragem, ${ }^{7}$ desenvolvem-se as "lawtechs" e "legaltechs", especializadas em engenharia de "softwares" voltadas ao mercado jurídico.

\footnotetext{
${ }^{5}$ Para uma exposição das principais causas da crise numérica do Poder Judiciário brasileiro, remeta-se a ROQUE, Andre Vasconcelos. A luta contra o tempo nos processos judiciais: um problema ainda à busca de uma solução, Revista eletrônica de direito processual, n. 7, 2011, p. 246-247: "Sem a preocupação de apresentar uma lista exaustiva, as principais causas para o descumprimento da promessa de duração razoável do processo são de ordem: a) estrutural (falta de verbas, recursos humanos e de autonomia financeira do Judiciário; gestão ineficiente dos escassos recursos pelos tribunais, visto que realizada por magistrados, com formação exclusivamente jurídica e que não receberam qualquer treinamento para as tarefas administrativas; comodismo dos juízes, formados através de um sistema generalista e pragmático, que tem por objetivo a aprovação dos disputados concursos públicos, mas não à formação de magistrados participativos e diligentes); b) técnica (desprestígio das decisões de primeira instância pela ampla recorribilidade e pelo sistema rígido de preclusões do Código de Processo Civil; formalismo exagerado de algumas normas processuais e de determinados entendimentos jurisprudenciais; regulamentação ineficiente para as lides de natureza coletiva, podendo gerar milhares ou mesmo milhões de demandas individuais repetitivas); c) sócio-política (explosão da litigiosidade após a Constituição de 1988, como resultado não apenas da intensificação dos fluxos de pessoas, bens e informações e do processo de redemocratização no Brasil, mas também pela progressiva universalização do acesso à justiça e pelo fortalecimento gradual - mas insuficiente - da assistência judiciária gratuita; existência de um Estado demandista, que não atende de forma voluntária as pretensões dos jurisdicionados, ainda que sobre temas já pacificados na jurisprudência, interessando-se mais em protelar suas obrigações, o que ocasiona congestionamentos sobretudo na Justiça Federal)".

${ }^{6} \mathrm{https} / / /$ www.cnj.jus.br/pesquisas-judiciarias/justica-em-numeros/, acesso em 30.5.2020.

${ }^{7}$ Nesse sentido, dispõe o art. $3^{\circ}, \S 3^{\circ}$ do CPC que a "conciliação, a mediação e outros métodos de solução consensual de conflitos deverão ser estimulados por juízes, advogados, defensores públicos e membros do Ministério Público, inclusive no curso do processo judicial". Para Humberto Dalla, a busca da pacificação dos conflitos, com a utilização de meios consensuais, configura a quinta fase metodológica do processo civil brasileiro (PINHO, Humberto Dalla Bernardina de. Jurisdição e pacificação - limites e possibilidade do uso
} 
As empresas do setor apresentam a inteligência artificial como uma sedutora alternativa ao descontingenciamento de processos, especialmente relacionados aos litígios de massa, bem como de redução de custos, além de permitir um melhor aproveitamento do tempo pelos humanos.

Ocorre que, até o presente momento, muito embora haja um especial incentivo por parte do CNJ na implementação da inteligência artificial pelos tribunais do país, através da plataforma SINAPSES, desenvolvida em conjunto com o Tribunal de Justiça de Rondônia TJRO, é certo que o tema ainda carece de regulamentação. ${ }^{8}$ Nessa direção, o uso descomedido da tecnologia pode encontrar barreiras no sistema de garantias constitucionais, notadamente voltadas ao devido processo legal constitucional.

Dessa forma o presente estudo tem o objetivo de estimular a reflexão acerca do uso da tecnologia da informação, mais especificamente da inteligência artificial, na resolução de conflitos pelo Poder Judiciário, demonstrando os seus benefícios, mas também alertando o leitor para o risco do "decisionismo tecnológico" - vale dizer, o perigo de a tecnologia ser utilizada não como auxílio para a tomada de decisões, mas sim para que sejam tomadas decisões de forma inteiramente automatizadas

Nessa direção, serão propostas algumas premissas como forma de harmonizar a tecnologia e o devido processo legal constitucional.

Antes, contudo, de apresentar os possíveis riscos que poderão exsurgir a partir do uso desenfreado da inteligência artificial, e as respectivas propostas, ainda que tímidas, em termos de futura regulamentação para mitigar os riscos apontados, abordar-se-ão os seus principais benefícios.

\footnotetext{
dos meios consensuais de resolução de conflitos na tutela dos direitos transindividuais e pluri-individuais. Curitiba: CRV, 2017, p. 95 e ss.).

8 “A plataforma Sinapses, desenvolvida pelo Tribunal de Justiça de Rondônia (TJRO), constitui-se num modelo unificado para construir soluções e prover IA. Por meio de um termo de cooperação técnica, servidores daquela unidade estão no CNJ para desenvolvimento e funcionamento de IA num ambiente de nuvem para atendimento de todos os tribunais do país. O passo seguinte foi o chamamento público, por meio de edital, para que os tribunais trabalhem com o CNJ por meio de propostas, desenvolvimento e produção de IA" (Fonte: https://www.cnj.jus.br/inovacoes-em-inteligencia-artificial-para-o-pje-sao-apresentadas-no-cnj/, acesso em 30.5.2020).

${ }^{9}$ Expressão concebida em um contexto de incremento das desigualdades em caso de utilização de decisões proferidas por meio de máquinas. Sobre o ponto, remeta-se a NUNES, Dierle; MARQUES, Ana Luiza Pinto Coelho. Inteligência artificial e direito processual: vieses algorítmicos e os riscos de atribuição de função decisória às máquinas, Revista de Processo, n. 285, pp. 421-447, nov. 2018.
} 


\section{Os principais aspectos e benefícios da inteligência artificial aplicada ao Direito}

A inteligência artificial, reconhecida como a aptidão das máquinas em realizar atividades que se aproximam ou procuram imitar a inteligência humana, apesar de ser uma das grandes ambições dos pesquisadores desde a década de 50, apresenta-se, mais do que nunca, como uma das principais ferramentas da Quarta Revolução Industrial, também chamada de Revolução Digital. ${ }^{10}$ Trata-se de estágio da evolução tecnológica em que se busca uma simbiose entre o mundo físico, digital e biológico, marcada essencialmente pela cibernética, considerando-se a grande quantidade de dados que são produzidos ${ }^{11}$.

Os ideais, portanto, de otimização do tempo x redução de custos, bem como de incremento na produção $\mathrm{x}$ acurácia de resultados, propiciados pela automatização de processos, são de interesse de todos os setores produtivos. Decerto, o Poder Judiciário não poderia resistir a esse fenômeno da virada tecnológica, ainda mais diante do contingente avassalador de processos judiciais em andamento no Brasil e da intensificação na adoção de meios virtuais e de outras tecnologias estimulada pela recente pandemia da Covid-19, com a consequente impossibilidade, durante o período de isolamento social, do comparecimento pessoal de juízes, das partes e de seus advogados para a realização de atos processuais.

No Direito, a inteligência artificial é utilizada por meio da estruturação de algoritmos, os quais se caracterizam como um procedimento lógico voltado à solução de determinado problema, tendo como ponto de partida os dados que são fornecidos ao sistema - input como, por exemplo, os padrões de fatos, os padrões de documentos, os julgados e os precedentes, e como ponto de chegada - output - o resultado alcançado. ${ }^{12}$ Esse ponto de

\footnotetext{
${ }^{10}$ https://www.atse.org.au/news-and-events/article/why-we-need-a-cybernetic-future/, acesso em 30.5.2020.

${ }^{11}$ DRUMMOND, Marcílio Henrique Guedes. O direito dataísta. In: FONSECA, Isabella et al. Inteligência artificial e processo. Belo Horizonte: D’Placido, 2019, p. 120.

12 Sobre o ponto: “(...) é necessário estabelecer o mecanismo de entrada de dados (input). Um algoritmo deve ter um ou mais meios para recepção dos dados a serem analisados. Em uma máquina computacional, a informação deve ser passada para o computador em meio digital (bits). Do mesmo modo, é necessário ter um mecanismo para a saída ou retorno dos dados trabalhados (output). Um algoritmo deve ter um ou mais meios para retorno dos dados, os quais devem estar relacionados de modo específico com o input. Por exemplo, um algoritmo de uma calculadora que receba as informações para somar 2+2 (input) irá retornar como resultado o número 4 (output). O output decorre do input, sendo papel do algoritmo fornecer o retorno dos dados corretos a partir dos dados de entrada. Uma vez que o algoritmo não faz nenhum juízo de valor para além de sua programação, é necessário que a relação de "correção" entre o input e o output seja definida de modo preciso e sem ambiguidade. Por isso, os algoritmos precisam ter cada passo de suas operações cuidadosamente definido. Assim, cada passo da tarefa computacional deve seguir um roteiro de tarefas pré-determinado e o programa (computação dos dados) deve terminar depois que o roteiro seja cumprido. O algoritmo tem que ser finito, ou seja, entregar algum retorno (output) após cumpridos todos os passos estabelecidos. Para cumprir a tarefa adequadamente, cada operação que o algoritmo tiver que realizar deve ser simples o suficiente para que
} 
chegada poderá ser desde uma simples análise ou confecção de documentos, contratos e de petições a até mesmo a facilitação de identificação de demandas repetitivas e a predição de possíveis julgamentos futuros por meio de métodos quantitativos e estatísticos das decisões e dos precedentes - o que se conhece como jurimetria.

A jurimetria nada mais é do que a estatística aplicada ao direito, utilizada em conjunto com softwares jurídicos para tentar prever resultados e oferecer probabilidades de resolução dos litígios em determinado sentido. Essa talvez seja uma das grandes apostas da tecnologia para o descontingenciamento processual, uma vez que permitirá, como já dito, não só a antecipação de possíveis resultados, como também terá o condão de auxiliar os juízes na tomada de decisões. Já para a advocacia impactará positivamente no aconselhamento aos clientes - inclusive sugerindo as melhores condições para eventual solução consensual de seus conflitos -, porquanto os advogados terão uma visão global sobre os casos envolvendo determinada temática, podendo predizer o entendimento do Poder Judiciário, e mesmo de determinado magistrado, sobre a questão, ao invés de terem que se pautar única e exclusivamente em sua experiência prático-profissional, que pode estar enviesada por uma visão incompleta do profissional do Direito.

Acredita-se, nessa direção, que a predição de resultados pode desestimular a judicialização de demandas com baixa probabilidade de êxito, favorecer a autocomposição e, por vezes, o reconhecimento jurídico do pedido pelo réu com o consequente cumprimento da prestação, haja vista que o Código de Processo Civil prevê uma sanção premial consistente na redução pela metade dos honorários advocatícios devidos ao patrono da outra parte, de acordo com a previsão do $\$ 4^{\circ}$, do art. 90 desse diploma. Para além disso, pode desestimular a interposição de recursos com baixa probabilidade de êxito, devido à previsão dos honorários de sucumbência recursais, na forma do art. 85, § 11 do CPC.

Além disso, a jurimetria pode se revelar como um importante mecanismo de controle - accountability - das decisões judiciais e, por via de consequência, do Poder Judiciário. Isso porque permitirá a fiscalização na observância aos precedentes, bem como eventuais desvios de comportamento ${ }^{13}$, seja por desrespeitar o sistema de precedentes, seja por mudanças

possa ser realizada de modo exato e em um tempo razoável (finito) por um ser humano usando papel e caneta(...)" (NUNES, Dierle; MARQUES, Ana Luiza Pinto Coelho. Inteligência artificial e direito processual... Op. Cit., p. 3 (versão eletrônica)).

${ }^{13}$ Nada obstante, na França foi proibida a análise de dados estatísticos relacionados ao Judiciário, notadamente mediante o emprego de inteligência artificial para, com base em dados públicos, tentar prever o resultado de 
injustificadas de posicionamento anteriormente adotado, sem a devida demonstração da distinção (distinguishing) do caso concreto examinado, nem da superação (overruling) do precedente a ser considerado. Vale dizer, qualquer quebra de padrão decisório poderá ser facilmente identificável, de modo que os juízes terão que estar atentos às transformações causadas pela jurimetria.

No Brasil, já é possível encontrar diversas instituições, públicas e privadas, valendose da inteligência artificial no Direito.

A título de exemplo, no escritório Urbano e Vitalino, sediado em Recife (PE), a assistente virtual "Carol" - que se utiliza da plataforma WATSON, desenvolvida pela IBM -, tem como principal função realizar serviços repetitivos, incrementando, sobremaneira, a média de acertos nos serviços de preenchimento de dados em relação aos advogados. A assistente virtual, ainda, deverá ter a sua experiência ampliada para viabilizar a análise rápida de documentos, o resumo de peças processuais, entre outras atividades, de forma que se espera um aumento de $30 \%$ (trinta por cento) na produtividade do escritório a médio prazo ${ }^{14}$.

Já na advocacia pública, mais especificamente na Advocacia-Geral da União (AGU), foi implantado o Sistema de Apoio à Procuradoria Inteligente - SAPIENS. A ferramenta de inteligência teve como objetivo facilitar o trabalho dos procuradores e servidores, o que se dá por meio da implementação de rotinas de inteligência capazes de realizar a triagem de processos, promover a indicação de teses relacionadas aos casos concretos e, inclusive, auxiliar na elaboração de peças judiciais e pareceres. ${ }^{15}$

No âmbito do Poder Judiciário, o Supremo Tribunal Federal - STF lançou mão do VICTOR, ${ }^{16}$ programa de inteligência artificial desenvolvido em parceria com a Universidade de Brasília - UnB. O nome atribuído foi uma homenagem ao Min. Victor Nunes Leal, em razão de ter sido um dos primeiros ministros a se preocupar com a unificação da

\footnotetext{
julgamentos. O art. 33 da Lei de Reforma do Judiciário daquele país dispõe: “Os dados de identidade de magistrados e membros do registro não podem ser reutilizados com o objetivo ou efeito de avaliar, analisar, comparar ou prever suas práticas profissionais reais ou supostamente. A violação desta proibição é punível com as penas previstas nos artigos 226-18.226-24 e 226-31 do Código Penal, sem prejuízo das medidas e sanções previstas na lei ${ }^{\circ}{ }^{78-17}$ de 6 de janeiro de 1978, relativa ao processamento de dados, arquivos e liberdades" (Fonte: https://www.conjur.com.br/2019-jun-05/franca-proibe-divulgacao-estatisticas-decisoesjudiciais e https://www.legifrance.gouv.fr/eli/loi/2019/3/23/2019-222/jo/article_33 , acessos em 4.8.2020). 14 https://ab2l.org.br/inteligencia-artificial-da-ibm-ja-ajuda-advogados-brasileiros/, acesso em 5.8.2020.

15 https://agu.jusbrasil.com.br/noticias/100556940/advocacia-geral-da-uniao-vai-utilizar-ferramenta-cominteligencia-artificial-e-automacao-de-processos-em-todo-o-brasil, acesso em 30.5.2020.

${ }^{16} \mathrm{http}: / /$ www.stf.jus.br/portal/cms/verNoticiaDetalhe.asp?idConteudo=388443, acesso em 30.5.2020.
} 
jurisprudência e com a identificação dos temas repetitivos. O VICTOR tem a função de aumentar a eficiência e velocidade na avaliação judicial de processos que chegam à corte, identificando as vinculações aos temas de repercussão geral. Atualmente, o software já é capaz de avaliar os recursos extraordinários que se enquadrarem em um dos 27 (vinte e sete) temas que foi ensinado a identificar e de forma muito mais ágil do que os servidores. ${ }^{17}$

Ainda, o sítio on-line do Tribunal de Justiça de Minas Gerais divulgou em matéria publicada no ano de 2018 que a $8^{\mathrm{a}}$ Câmara Cível julgou, com apenas um único clique, um total de 280 (duzentos e oitenta) processos, valendo-se da ferramenta RADAR aplicada aos recursos similares. ${ }^{18}$ No caso, referida ferramenta identificou e separou recursos com idênticos pedidos, montando um padrão de voto que contempla matéria já decidida pelos Tribunais Superiores ou em Incidente de Resolução de Demandas Repetitivas (IRDR). Esse esboço de voto é apresentado ao desembargador relator, que tem a possibilidade de fazer alterações e imprimir seu traço pessoal ao texto. Feitas as correções, a máquina já identifica os recursos iguais e procede ao julgamento conjunto, em questão de segundos.

Discute-se, por outro lado, se a utilização da jurimetria como uma ferramenta de controle do Poder Judiciário não poderia acabar por engessar o sistema de precedentes judiciais, dificultando a demonstração da distinção entre o caso concreto e o precedente distinguishing - ou da superação do precedente - overruling. ${ }^{19}$ Não é difícil imaginar, da mesma forma, uma possível tendência ao tabelamento das indenizações, ficando relegadas a segundo plano as circunstâncias individuais do caso concreto e das partes envolvidas.

Ainda, por conta dos benefícios e da comprovada aptidão dos sistemas de inteligência artificial no desempenho de tarefas que até alguns anos atrás seriam exclusivamente

17 https://www.jota.info/coberturas-especiais/inova-e-acao/stf-aposta-inteligencia-artificial-celeridadeprocessos-11122018, acesso em 30.5.2020.

18 https://www.tjmg.jus.br/portal-tjmg/noticias/tjmg-utiliza-inteligencia-artificial-em-julgamentovirtual.htm\#.Xj-IoFVKjIV, acesso em 30.5.2020.

${ }^{19}$ Nesse sentido: "A confluência de um sistema de precedentes obrigatórios e um algoritmo de Inteligência Artificial decisória pode resultar na total impossibilidade de superação de precedentes judiciais, afinal, o direito é aquilo que os tribunais dizem que é, para lembrar do realismo jurídico, que se mostrou incorrigivelmente insatisfatório. Lembre-se, neste momento que os precedentes não são virtuosos por si só e o que os tribunais decidem nem sempre é correto, motivo pelo qual um processo verdadeiramente democrático demanda a possibilidade de revisitação dos atos decisórios estatais, sem que isso represente, necessariamente, uma anarquia jurisprudencial" (VIANA, Antônio Aurélio de Souza. Juiz-robô e a decisão algorítmica: a inteligência na aplicação dos precedentes. In: FONSECA, Isabella et al. Inteligência artificial e processo. Belo Horizonte: D’Placido, 2019, p. 39). 
realizáveis por seres humanos, chegou-se a cogitar que os advogados pudessem ser substituídos pelas máquinas - mesmo fora das tarefas repetitivas do contencioso de massa.

A notícia da criação do programa chamado COIN - Contrato de Inteligência - pelo Banco JPMorgan, uma das maiores instituições financeiras do mundo, foi encarada de início como uma verdadeira ameaça aos advogados, pois esse programa, além de poder trabalhar de forma ininterrupta e ser pouco propenso a erros, interpretou acordos de empréstimo comercial em segundos, algo que consumia cerca de 360 (trezentos e sessenta) mil horas por ano dos advogados ${ }^{20}$.

Outra notícia impactante foi o resultado da competição travada entre vinte advogados humanos e a inteligência artificial, decorrente do desafio de quatro horas para revisão de cinco acordos de confidencialidade - non disclousure agréments -, promovido pelas Universidades de Stanford, Duke e do Sul da Califórnia, todas dos Estados Unidos, em parceria com a Lawgeex, startup de tecnologia jurídica. Nessa competição restou evidenciado que os robôs não apenas foram mais precisos que os humanos, como também realizaram a tarefa em tempo infinitamente menor, no caso em apenas 26 (vinte e seis) segundos, contra 92 (noventa e dois) minutos, em média, pelos humanos. ${ }^{21}$

Sem embargo de tais preocupações e apesar dos evidentes impactos que a utilização dos sistemas de inteligência artificial no meio jurídico pode trazer para a empregabilidade de advogados que trabalham com contencioso de massa, tais mecanismos foram concebidos essencialmente para somar, facilitando a rotina dos profissionais (sobretudo nas tarefas repetitivas) e liberando mais tempo para que possam se dedicar a atividades intelectuais e criativas.

O maior risco, sob a perspectiva das garantias fundamentais do processo, reside na possibilidade de se implementar a inteligência artificial para a tomada de decisões de forma totalmente automatizada, o que parece ser um caminho natural do desenvolvimento do machine learning - aprendizado de máquina, sem a interferência humana, por meio da experiência obtida em função dos parâmetros já alcançados anteriormente. Afinal, seguindo essa lógica utilitarista, de pouco adiantaria a aceleração da marcha procedimental, por meio

\footnotetext{
${ }^{20}$ https://www.itforum365.com.br/sistema-do-jpmorgan-realiza-em-segundos-o-que-advogados-levaram-360mil-horas/, acesso em 30.5.2020.

21 https://www.conjur.com.br/2018-nov-21/inteligencia-artificial-bate-20-advogados-revisao-contratos, acesso em 30.5.2020.
} 
da execução automatizada dos atos processuais repetitivos e de menor complexidade, se, ao final, os processos ficassem represados nos gabinetes dos julgadores para a tomada de decisões - ainda que seja para acolher o padrão decisório sugerido pelos algoritmos.

Por esse motivo pensa-se agora em algumas premissas para assegurar que, uma vez que a inteligência artificial seja utilizada não como simples auxílio, mas para a tomada de decisões automatizadas pelo Poder Judiciário, tal providência não implique em violação às garantias fundamentais do processo e a completa perda de sua humanização.

\section{A inteligência artificial na tomada de decisões e as três premissas básicas para sua utilização}

Inicialmente, cumpre já afastar a falsa acepção no sentido de que as decisões tomadas por meio de máquinas seriam neutras - isto é, mais do que imparciais, uma vez que estariam livres de experiências humanas -, como forma de legitimar a sua aplicabilidade nos processos judiciais.

Isso porque, para além de ser indesejável a perda absoluta de humanização na administração da justiça, os dados (inputs) que alimentam a inteligência artificial são frutos de interpretações humanas e, portanto, a depender de sua qualidade, bem como dos anseios dos seus programadores ou até da complexa forma como se desenvolveu o procedimento lógico do algoritmo, seria perfeitamente possível obter decisões por demais subjetivas, eivadas de ilegalidades, levando aos chamados "algoritmos enviesados".

Com efeito, os algoritmos enviesados são aqueles que apresentam padrões deturpados em sua formação e se mostram bastante perigosos. Sob a falsa aparência de neutralidade, acabam por perpetuar vieses difíceis de serem percebidos, eventualmente até mesmo por seus programadores, carecendo da transparência necessária. O resultado é a legitimação, por meio da tecnologia, de tratamentos desiguais e discriminatórios, que se encontram como um dado real na sociedade e acabam sendo absorvidos pelos algoritmos.

Apenas a título de exemplo, em estudo publicado na revista Science, cientistas acompanharam a evolução de um software voltado para a área da saúde, que indicava a 
ordem de prioridade dos pacientes em fila para receber atendimento. O resultado observado foi um viés racial, que desfavorecia pessoas negras nos algoritmos do sistema. ${ }^{22}$

Outro exemplo de enviesamento observado foi nos algoritmos de reconhecimento facial. Observou-se que a ocorrência de falsos positivos (quando o software aponta serem a mesma pessoa dois rostos diferentes) em programas desenvolvidos nos Estados Unidos era de 10 a 100 vezes maior para rostos de pessoas asiáticas e afro-americanos, em comparação a pessoas caucasianas. Já algoritmos desenvolvidos por empresas asiáticas apresentaram menos falsos positivos em verificações "um para um" entre faces asiáticas e caucasianas, o que provavelmente se deve ao fato de estas usarem bases de dados mais diversas para treinar seus algoritmos. ${ }^{23}$

Adentrando no campo jurídico, o mesmo aconteceu com o sistema Correctional Offender Management Profiling for Alternative Sanctions - COMPASS, utilizado nos Estados Unidos com o objetivo de avaliar o risco de reincidência, auxiliando, assim, na fixação da pena do acusado, levando-se em conta que quanto maior fossem os indicativos de reincidência, maior seria o tempo da reprimenda que deveria ser imposta pelo Estado. Verificou-se que o sistema possuía um viés social discriminatório, considerando os acusados negros como mais propensos à reincidência em comparação aos acusados brancos, sendo certo que o referido sistema não garantia ao acusado acesso aos dados relacionados ao procedimento computacional que levou a tal conclusão. ${ }^{24}$

A preocupação com a transparência dos algoritmos mostrou-se tão importante que já foi objeto da Resolução do Parlamento Europeu, de 16 de fevereiro de 2017, contendo recomendações à Comissão de Direito Civil sobre Robótica, sendo que, dentre as recomendações, a de $n^{\circ} 12$ realça o princípio ético da transparência, apontando que, em linhas gerais, a tomada de decisão, que se valha da inteligência artificial e cause impacto substancial na vida de uma ou mais pessoas, deve viabilizar a redução de tais mecanismos de inteligência a uma forma compreensível pelos seres humanos. ${ }^{25}$

\footnotetext{
22 https://jornal.usp.br/radio-usp/colunistas/inteligencia-artificial-ainda-sofre-com-algoritmos-enviesados/, acesso em 30.5.2020.

${ }^{23}$ https://gizmodo.uol.com.br/reconhecimento-facial-enviesados-estudo-eua/, acesso em 30.5.2020.

${ }^{24}$ NUNES, Dierle; MARQUES, Ana Luiza Pinto Coelho. Inteligência artificial e direito processual... Op. Cit., p. 7 (versão eletrônica).

${ }^{25}$ http://www.europarl.europa.eu/doceo/document/TA-8-2017-0051_PT.html\#title1, acesso em 30.5.2020.
} 
Frise-se que no ordenamento jurídico brasileiro, o princípio ético da transparência algorítmica revela-se como substrato do próprio princípio da publicidade (art. $5^{\circ}, \mathrm{LX}$ e 93 , IX da Constituição e art. $8^{\circ}$ do CPC). Se não há a devida transparência é impossível exercer controle - accountability - sobre a adequada utilização da inteligência artificial.

E, para além disso, a ausência de transparência também prejudica o próprio exercício do direito de ação e do contraditório, em sua dimensão de influência sobre o convencimento do julgador (contraditório participativo), ${ }^{26}$ na medida em que traz obstáculos à parte derrotada no processo, os quais impedem o exercício desses direitos em sua plenitude, por não lhe ser possível compreender o processo de formação do algoritmo que levou à tomada da decisão prejudicial a seus interesses.A preocupação se agrava, no campo jurídico, quanto ao conteúdo das decisões tomadas por intermédio de "softwares", tendentes a buscar padrões, em casos específicos, o que poderia, em última análise, levar à “industrialização das decisões judiciais", afastando-se cada vez mais da riqueza de elementos que os casos concretos apresentam. ${ }^{27}$

Imagine-se, ainda, se essa decisão, tomada com base em inteligência artificial, fosse omissa e contra ela aviados Embargos Declaratórios, posteriormente rejeitados, valendo-se da mesma lógica algorítmica, ou seja, novamente por sistemas automatizados e sem respeitar os elementos específicos do caso concreto.

\footnotetext{
${ }^{26}$ Sobre a noção de contraditório participativo, embora nem sempre adotando tal terminologia, confira-se ROQUE, Andre Vasconcelos. Contraditório participativo: evolução, impactos no processo civil e restrições. Revista de Processo, n. 279, p. 1-140, mai. 2018; THEODORO JR., Humberto et al. Novo CPC - Fundamentos e sistematização. Rio de Janeiro: Forense, 2015. p. 104 e ss.; BEDAQUE, José Roberto dos Santos. Os elementos objetivos da demanda examinados à luz do contraditório. In: CRUZ E TUCCI, José Rogério; BEDAQUE, José Roberto dos Santos (Coord.). Causa de pedir e pedido no processo civil. São Paulo: Revista dos Tribunais, 2002., p. 20-23; GRECO, Leonardo. Instituições de processo civil. Rio de Janeiro: Forense, 2015. v. I, p. 513/514; DIDIER JR., Fredie. Curso de Direito Processual Civil. Salvador: Juspodivm, 2017. v. 1, p. 91-97; CABRAL, Antonio do Passo. Contraditório. In: TORRES, Ricardo Lobo; KATAOKA, Eduardo Takemi; GALDINO, Flávio (Org.). Dicionário de princípios jurídicos. Rio de Janeiro: Elsevier, 2011. p. 193210 (apontando que o contraditório, para além do poder de influência, impõe deveres, como resultado da exigência de colaboração e participação dos sujeitos do processo). Criticando tal terminologia, DINAMARCO, Cândido Rangel; LOPES, Bruno Vasconcelos Carrilho. Teoria geral do novo processo civil. São Paulo: Malheiros, 2016. p. 62 (apontando que não se concebe contraditório que não seja "participativo").

27 Nesse sentido remeta-se VIANA, Antônio Aurélio de Souza. Juiz-robô e a decisão algorítmica... Op. Cit., p. 27. "Por um lado, a aplicação da estatística ao Direito poderia significar o pleno alcance da estabilidade, igualdade e previsibilidade, a partir da compreensão do modo como decidem os tribunais. Por outro ângulo, poderia representar um incremento da desigualdade entre litigantes habituais e litigantes eventuais. E, num cenário ainda mais corrosivo, a jurimetria, alinhada aos precedentes obrigatórios, poderia ensejar um engessamento do Direito em função de uma possível aplicação irrefletida”.
} 
Para piorar o panorama, considere-se ainda que os procuradores das partes não tenham sido informados pelo Poder Judiciário sobre a utilização dos meios artificiais de tomada de decisão - não haveria sério risco às garantias fundamentais do processo? Eis o ponto central de nossa reflexão sobre o assunto.

Para mitigar esses riscos, propõem-se três premissas básicas para a utilização da inteligência artificial como ferramenta para a tomada de decisões pelo Poder Judiciário.

Em primeiro lugar, considerando que as decisões e os julgamentos proferidos pelos juízes devem ser públicos - e mesmo nos excepcionais casos de segredo de justiça deve ser assegurado o acesso dos atos processuais às partes e seus procuradores, na forma do arts. 11, parágrafo único e $189, \S 1^{\circ} 1^{\circ}$ do CPC - exsurge nossa premissa inicial: toda decisão judicial tomada com o auxílio de inteligência artificial deve conter essa informação em seu corpo.

Aliás, dentre as normas fundamentais, o Código de Processo Civil elencou o princípio da cooperação em seu art. $6^{\circ}$, sendo certo que o dever de informação constitui um dos corolários mais importantes deste princípio, que coloca a tônica da divisão de trabalho no diálogo entre todos os sujeitos do processo. Estrutura-se o processo contemporâneo em uma comunidade de trabalho (Arbeitsgemeinschaft), em que todos os sujeitos podem e devem contribuir para o exercício da função jurisdicional. ${ }^{28}$ As partes não detêm a primazia dos direitos e faculdades processuais (como no modelo dispositivo), nem o juiz concentra os poderes em suas mãos (como no modelo inquisitório). Há no modelo cooperativo verdadeiro policentrismo, ${ }^{29}$ ficando o juiz no mesmo plano das partes para o debate processual e acima delas apenas no momento em que toma sua decisão, como o ato final de exercício do poder jurisdicional.

Uma vez fornecida a informação de que a decisão foi apoiada por mecanismos artificiais, fica mais fácil compreender o porquê da existência de eventuais vícios de fundamentação na decisão judicial. De todo modo, para ampliar as chances de êxito na oposição dos Embargos de Declaração (art. 1.022 do CPC/2015), os advogados precisariam compreender a lógica algorítmica, conhecendo os dados e os elementos levados em consideração para a formação daquele padrão decisório, sem o que teriam que recorrer às cegas, em razão da opacidade algoritimica. Recomenda-se, dessa maneira, que os tribunais

\footnotetext{
${ }^{28}$ ROSENBERG, Leo. Tratado de Derecho Procesal Civil. Trad. Angela Romera Vera. Buenos Aires: EJEA, 1955. t. I, p. 8.

${ }^{29}$ PICARDI, Nicola. Manuale del processo civile. Milano: Giuffrè, 2006. p. 208.
} 
sejam mais transparentes quanto aos dados considerados em suas ferramentas de inteligência artificial.

De mais a mais, além de a informação de que foi utilizada a inteligência artificial ser direito do jurisdicionado, mais do que apenas do advogado, também é seu direito fiscalizar se o caso se adequa ao emprego de tal ferramenta, mecanismo esse cuja utilização deve se restringir aos casos repetitivos, retirando-se da vala comum os processos com diferentes abordagens (hipóteses em que o distinguishing humano precisará ser realizado, sob pena de omissão) ou aqueles que envolvem questões inovadoras, até então não apreciadas pelo Judiciário.

Passando à segunda premissa de nosso raciocínio, não se pode olvidar que a garantia do acesso à justiça, prevista no inciso XXXV, do art. $5^{\circ}$, da Constituição, em seu aspecto formal, pressupõe o acesso ao Poder Judiciário, cuja organização vem pré-estabelecida no texto constitucional - princípio do juiz natural ${ }^{30}$-, personificado em seus juízes, devidamente aprovados em concurso público de provas e títulos para o ingresso na magistratura. Em síntese, o Poder Judiciário não pode prescindir da necessária humanização.

Portanto, somente a partir dessa breve análise, já se pode estabelecer mais uma premissa: seria inconstitucional a tomada de decisões exclusivamente por robôs, sem que suas decisões sejam de alguma forma submetidas à revisão humana, sendo assegurado pela Carta Magna o direito público subjetivo de acesso aos juízes.

Ainda no campo da garantia fundamental do acesso à justiça, agora em seu aspecto material, é certo que tal garantia não se resume apenas a um direito subjetivo de se obter uma decisão judicial em caso de lesão ou ameaça à direito - qualquer que seja seu conteúdo -, mas sim uma ordem jurídica justa, ${ }^{31}$ que seja efetivamente capaz de pacificar o conflito estabelecido entre as partes, permitindo que a parte prejudicada não apenas se submeta ao comando judicial, como também que tal tutela se mostre adequada. ${ }^{32}$

\footnotetext{
${ }^{30}$ Sobre o acesso à justiça em seu sentido estrutural remeta-se a THEODORO JUNIOR, Humberto. Curso de direito processual civil: teoria geral do direito processual civil, processo de conhecimento e procedimento comum. Vol. 1. Rio de Janeiro: Forense, 2017, p. 74: "Nele se englobam tanto as garantias de natureza individual, como as estruturais, ou seja, o acesso à justiça se dá, individualmente, por meio do direito conferido a todas as pessoas naturais ou jurídicas de dirigir-se ao Poder Judiciário e dele obter resposta acerca de qualquer pretensão, contando com a figura do juiz natural e com sua imparcialidade".

31 WATANABE, Kazuo. Acesso à justiça e sociedade moderna. In: GRINOVER, Ada Pellegrini et al. Participação e Processo. São Paulo: Revista dos Tribunais, 1985, p. 128.

${ }^{32}$ MARINONI, Luiz Guilherme. Teoria Geral do Processo. São Paulo: Revista dos Tribunais, 2008, p. 215.
} 
Nesse sentido, o art. 93, inciso IX, da CF/1988 e o art. 11 do Código de Processo Civil de 2015 - CPC/2015 são imperativos ao estabelecerem que todos os atos decisórios emanados do Poder Judiciário serão públicos e fundamentados, sob pena de nulidade. $\mathrm{O} \S 1^{\circ}$, do art. 489, do CPC/2015, inclusive, atribuindo a merecida importância ao princípio da motivação das judiciais, descreve hipóteses concretas em que as decisões judiciais não serão consideradas fundamentadas.

Deste modo, se os sistemas de inteligência artificial, por mais desenvolvido que seja o "machine learning", não lograrem entregar uma decisão que consiga apreciar todas as particularidades do caso ou se não enfrentarem os argumentos deduzidos nos autos pelas partes, capazes de influenciar na convicção do julgador, ainda que seja para rejeitá-los, não será possível adotá-los na tomada de decisões, sob pena de manifesta violação à exigência de motivação das decisões judiciais.

Nessa perspectiva, a utilização das maquinas ficaria reservada, no máximo, para o fim de auxiliar os juízes, por meio de tarefas laterais, na construção de suas decisões, visando a otimizar o tempo de pesquisas e de identificação de julgamentos inseridos no contexto do novel sistema vinculação aos precedentes judiciais, entre outras situações.

Nesse sentido, estabelece o art. $4^{\circ}$ do projeto de lei no 5051/2019, em trâmite no Senado Federal, de autoria do senador Styvenson Valentim, que "os sistemas decisórios baseados em Inteligência Artificial serão, sempre, auxiliares à tomada de decisão humana", tornando os supervisores, que se utilizaram do aludido sistema, responsáveis pelos danos decorrentes. ${ }^{33}$

Sendo assim, conjugando a necessidade de motivação específica com a publicidade necessária ao controle dos atos judiciais, o que inclui a transparência algorítmica, pode-se alcançar uma terceira premissa: sempre que opostos Embargos de Declaração invocando a ocorrência de obscuridade, contradição, omissão ou erro material contra decisão proferida com o auxílio de inteligência artificial assim atestada, estes deverão ser apreciados pelo juiz

\footnotetext{
${ }^{33} \mathrm{https} / /$ www25.senado.leg.br/web/atividade/materias/-/materia/138790, acesso em 30.5.2020. Apesar disso, na Lei Geral de Proteção de Dados (LGPD - Lei no 13.709/2018), o direito à revisão, por pessoa natural, de decisões tomadas unicamente com base em tratamento automatizado de dados pessoais que afetem os interesses de seu titular, o qual estava previsto em sua redação original, foi retirado por força da Lei $\mathrm{n}^{\circ} 13.853 / 1029$. O atual art. 20 da LGPD assegura ao titular dos dados pessoais tão somente o direito de revisão, mas não necessariamente por uma pessoa natural.
} 
da causa, sem a utilização de tal mecanismo, sob pena de nulidade. Em outras palavras, o direito de aclarar demanda revisão humana.

A premissa tal como lançada tem por objetivo permitir a reparação de todas as arestas ou lacunas eventualmente deixadas pelos algoritmos, bem como garantir o efetivo acesso à justiça em observância à segunda premissa colocada e, eventualmente, legitimar a aplicação da inteligência artificial para a tomada de decisões.

Como consequência disso, não é possível rejeitar o cabimento de Embargos de Declaração contra nenhum ato decisório tomado a partir da utilização de mecanismos de inteligência artificial, inclusive para as decisões de admissibilidade de recursos aos tribunais superiores, devendo ser superado o atual entendimento jurisprudencial em sentido contrário. ${ }^{34}$ Aliás, não há no Código de Processo Civil nenhum dispositivo que legitime tal interpretação dos tribunais superiores, vez que o art. 1.022 se refere, de forma ampla, a "qualquer decisão judicial".

Enfim, diante da ausência de regulamentação da inteligência artificial aplicada no auxílio ou na tomada direta de decisões judiciais, parece imprescindível a observância dessas três premissas básicas como forma de harmonizar a utilização desses "softwares" no âmbito do Poder Judiciário, sem ferir as garantias fundamentais do processo.

\section{Conclusão}

Dessume-se, a partir dessa breve reflexão, que, apesar de a inteligência artificial revelar-se como uma forte aliada na retomada na promoção e eficiência dos atos processuais, o seu avanço tecnológico sem a devida cautela pode-se revelar temerário. Dessa forma, ainda que reconhecendo que a utilização da inteligência artificial pode representar um caminho

\footnotetext{
34 Confira-se, exemplificativamente: "Processual civil. Agravo interno no agravo em recurso especial. Intempestividade. Embargos de declaração opostos à decisão denegatória de seguimento do recurso especial. Descabimento. Decisão mantida. 1. O prazo para interposição do agravo em recurso especial é de 15 (quinze) dias úteis, a teor do que dispõem os arts. 219, "caput", e 1.003, § 5º do CPC/2015. 2. "Esta Corte Superior entende que o único recurso cabível contra a decisão de admissibilidade do recurso especial é o agravo previsto no art. 1.042 do CPC/15. A interposição de embargos declaratórios não interrompe o prazo para a apresentação do referido agravo em recurso especial, por serem manifestamente incabíveis" (AgInt no AREsp 1370396/SP, Rel. Ministro Marco Buzzi, Quarta Turma, julgado em 12/02/2019, DJe 19/02/2019)" (STJ, AgInt no AREsp 1.081.043, Rel. Min. Antonio Carlos Ferreira, Quarta Turma, julg. 18.6.2019).
} 
sem volta do Poder Judiciário, buscou-se estabelecer premissas básicas para que o seu emprego respeite as garantias fundamentais do processo.

Nessa direção, estabeleceram-se como requisitos para a utilização da inteligência artificial na tomada de decisões judiciais: (i) toda decisão judicial tomada com o auxílio de inteligência artificial deve conter essa informação em seu corpo; (ii) decisões tomadas exclusivamente por robôs devem ser de alguma forma submetidas à revisão humana, sendo assegurado pela Carta Magna o direito público subjetivo de acesso aos juízes; e (iii) sempre que opostos Embargos de Declaração invocando a ocorrência de obscuridade, contradição, omissão ou erro material contra decisão proferida com o auxílio de inteligência artificial assim atestada, estes deverão ser apreciados pelo juiz da causa, sem a utilização de mecanismos de formulação automatizada de decisões judiciais, sob pena de nulidade.

Espera-se, com esta singela contribuição, compatibilizar a eficiência da inteligência artificial com as exigências do devido processo legal no ordenamento jurídico brasileiro.

\section{REFERÊNCIAS}

AB2L. Inteligência artificial da IBM já ajuda advogados brasileiros. Disponível em: https://ab2l.org.br/inteligencia-artificial-da-ibm-ja-ajuda-advogados-brasileiros/, acesso em 5.8.2020.

ALMEIDA, Daniel Evangelista Vasconcelos. Direito à explicação em decisões automatizadas. In: FONSECA, Isabella et al. Inteligência artificial e processo. Belo Horizonte: Editora D’Placido, 2019.

ATHENIENSE, Alexandre Rodrigues. As premissas para alavancar os projetos de inteligência artificial na justiça brasileira. Revista de Direito e as Novas Tecnologias, n.1, out./dez. 2018.

ATSE. Why we need a cybernetic future. Disponível em https://www.atse.org.au/news-andevents/article/why-we-need-a-cybernetic-future/, acesso em 30.5.2020.

BEDAQUE, José Roberto dos Santos. Os elementos objetivos da demanda examinados à luz do contraditório. In: CRUZ E TUCCI, José Rogério; BEDAQUE, José Roberto dos Santos (Coord.). Causa de pedir e pedido no processo civil. São Paulo: Revista dos Tribunais, 2002. 
CABRAL, Antonio do Passo. Contraditório. In: TORRES, Ricardo Lobo; KATAOKA, Eduardo Takemi; GALDINO, Flávio (Org.). Dicionário de princípios jurídicos. Rio de Janeiro: Elsevier, 2011.

CNJ. Justiça em Números - 2019. Disponível em: https://www.cnj.jus.br/pesquisasjudiciarias/justica-em-numeros/, acesso em 30.5.2020

CNJ. Inovações em Inteligência Artificial para o PJe são apresentadas no CNJ. Disponível em: $\quad$ https://www.cnj.jus.br/inovacoes-em-inteligencia-artificial-para-o-pje-saoapresentadas-no-cnj/, acesso em 30.5.2020

CONJUR. França proíbe divulgação de estatísticas sobre decisões judiciais. Disponível em: https://www.conjur.com.br/2019-jun-05/franca-proibe-divulgacao-estatisticasdecisoes-judiciais, acesso em 4.8.2020

CONJUR. Inteligência artificial bate 20 advogados em testes de revisão de contratos. Disponível em: https://www.conjur.com.br/2018-nov-21/inteligencia-artificial-bate20-advogados-revisao-contratos, acesso em 30.5.2020.

DE FRANCO, Theo Garcez de Martino Lins. A influência da inteligência artificial no sistema de precedentes judiciais. Revista de Direito e as Novas Tecnologias, n. 3, abr./jun. 2019.

DIDIER JR., Fredie. Curso de Direito Processual Civil. Vol. 1. Salvador: Juspodivm, 2017.

DINAMARCO, Cândido Rangel; LOPES, Bruno Vasconcelos Carrilho. Teoria geral do novo processo civil. São Paulo: Malheiros, 2016.

DRUMMOND, Marcílio Henrique Guedes, O direito dataísta. In: FONSECA, Isabella et al. Inteligência artificial e processo. Belo Horizonte: D’Placido, 2019.

FONSECA, Isabella Alves; ALMEIDA, Priscilla Brandão. Direito 4.0: uma análise sobre inteligência artificial, processo e tendências de mercado. In: FONSECA, Isabella et al. Inteligência artificial e processo. Belo Horizonte: D’Placido, 2019.

G1. Brasil tem mais faculdades de direito que China, EUA e Europa juntos; saiba como se destacar no mercado. Disponível em: https://g1.globo.com/educacao/guia-decarreiras/noticia/brasil-tem-mais-faculdades-de-direito-que-china-eua-e-europajuntos-saiba-como-se-destacar-no-mercado.ghtml, acesso em 30.5.2020. 
GIZMODO. Algoritmos de reconhecimento facial são enviesados, diz órgão dos EUA. Disponível em: https://gizmodo.uol.com.br/reconhecimento-facial-enviesadosestudo-eua/, acesso em 30.5.2020.

GRECO, Leonardo. Instituições de processo civil. Vol. I. Rio de Janeiro: Forense, 2015.

IT FORUM 365. Sistema do JPMorgan realiza em segundos o que advogados levaram 360 mil horas. Disponível em: https://www.itforum365.com.br/sistema-do-jpmorganrealiza-em-segundos-o-que-advogados-levaram-360-mil-horas/, acesso em 30.5.2020.

JORNAL DA USP. Inteligência artificial ainda sofre com algoritmos enviesados. Disponível em: https://jornal.usp.br/radio-usp/colunistas/inteligencia-artificial-ainda-sofre-comalgoritmos-enviesados/, acesso em 30.5.2020.

JOTA. STF investe em inteligência artificial para dar celeridade a processos. Disponível em: https://www.jota.info/coberturas-especiais/inova-e-acao/stf-aposta-inteligenciaartificial-celeridade-processos-11122018, acesso em 30.5.2020.

JUSBRASIL. Advocacia Geral da União vai utilizar ferramenta com inteligência artificial e automação de processos em todo o Brasil. Disponível em: https://agu.jusbrasil.com.br/noticias/100556940/advocacia-geral-da-uniao-vaiutilizar-ferramenta-com-inteligencia-artificial-e-automacao-de-processos-em-todo-obrasil, acesso em 30.5.2020.

LÉGIFRANCE. Loi $\mathrm{n}^{\circ}$ 2019-222 du 23 mars 2019. Disponível em: https://www.legifrance.gouv.fr/eli/loi/2019/3/23/2019-222/jo/article_33, acesso em 4.8.2020.

MARINONI, Luiz Guilherme. Teoria Geral do Processo. São Paulo: Revista dos Tribunais, 2008.

MIGALHAS. Brasil tem um advogado para cada 190 habitantes. Disponível em: https://www.migalhas.com.br/Quentes/17,MI312946,11049-

Brasil+tem+um+advogado+para+cada+190+habitantes, acesso em 5.8.2020.

NUNES, Dierle; MARQUES, Ana Luiza Pinto Coelho. Inteligência artificial e direito processual: vieses algorítmicos e os riscos de atribuição de função decisória às máquinas. Revista de Processo, n. 285, pp.421-447, nov. 2018.

NUNES, Dierle; DUARTE, Fernanda Amaral. Jurimetria e tecnologia: diálogos essenciais com o direito processual. Revista de Processo, n. 299, pp. 407-450, jan. 2020. 
ORDEM DOS ADVOGADOS DO BRASIL. Quadro de inscritos. Disponível em: https://www.oab.org.br/institucionalconselhofederal/quadroadvogados, acesso em 30.5.2020.

PARLAMENTO EUROPEU. Resolução do Parlamento Europeu, de 16 de fevereiro de 2017. Disponível em: http://www.europarl.europa.eu/doceo/document/TA-8-20170051_PT.html\#title1, acesso em 30.5.2020.

PICARDI, Nicola. Manuale del processo civile. Milano: Giuffrè, 2006.

ROQUE, Andre Vasconcelos. Contraditório participativo: evolução, impactos no processo civil e restrições. Revista de Processo, n. 279, p. 1-140, mai. 2018

ROSENBERG, Leo. Tratado de Derecho Procesal Civil. Trad. Angela Romera Vera. Buenos Aires: EJEA, 1955. t. I, p. 8.

SENADO FEDERAL. Atividade Legislativa - Projeto de Lei nº 5.051/2019. Disponível em: https://www25.senado.leg.br/web/atividade/materias/-/materia/138790, acesso em 30.5.2020.

SUPREMO TRIBUNAL FEDERAL. Ministra Cármen Lúcia anuncia início de funcionamento do Projeto Victor, de inteligência artificial. Disponível em: http://www.stf.jus.br/portal/cms/verNoticiaDetalhe.asp?idConteudo=388443, acesso em 30.5.2020.

THEODORO JUNIOR, Humberto et al. Novo CPC - Fundamentos e sistematização. Rio de Janeiro: Forense, 2015.

THEODORO JUNIOR, Humberto. Curso de direito processual civil: teoria geral do direito processual civil, processo de conhecimento e procedimento comum. Vol. 1. Rio de Janeiro: Forense, 2017.

TRIBUNAL DE JUSTIÇA DO ESTADO DE MINAS GERAIS. TJMG utiliza inteligência artificial em julgamento virtual. Disponível em: https://www.tjmg.jus.br/portaltjmg/noticias/tjmg-utiliza-inteligencia-artificial-em-julgamento-virtual.htm\#.XjIoFVKjIV, acesso em 30.5.2020.

VIANA, Antônio Aurélio de Souza. Juiz-robô e a decisão algorítmica: a inteligência na aplicação dos precedentes. In: FONSECA, Isabella et al. Inteligência artificial $e$ processo. Belo Horizonte: D’Placido, 2019. 
WATANABE, Kazuo. Acesso à justiça e sociedade moderna. In: GRINOVER, Ada Pellegrini et al. Participação e Processo. São Paulo: Revista dos Tribunais, 1985.

WAMBIER, Luiz Rodrigues. Inteligência artificial e sistema multiportas: uma nova perspectiva do acesso à justiça. Revista dos Tribunais, n. 1000, pp. 301-307, fev. 2019.

WOLKART, Erik Navarro; BECKER, Daniel. Tecnologia e precedentes: do portão de Kafka ao panóptico digital pelas mãos da jurimetria. In: FONSECA, Isabella et al. Inteligência artificial e processo. Belo Horizonte: D’Placido, 2019. 